\title{
Reaching Mental Health Research Participants with Multiple Stigmas; A Description of Strategies Used in a Depression Intervention Study for YMSM of Color with HIV
}

\author{
Eric Houston ${ }^{1,2^{*}}$, Chris Argueta ${ }^{1}$, Jahmil Lacey ${ }^{1}$, Sukrit Mukherjee ${ }^{1}$, Kieran Breda-Hill ${ }^{1}$ \\ ${ }^{1}$ Department of Psychiatry and Human Behavior, Charles R. Drew University of Medicine and Science, \\ Los Angeles, CA, USA \\ ${ }^{2}$ Department of Psychiatry and Biobehavioral Sciences, David Geffen School of Medicine at UCLA, \\ Los Angeles, CA, USA
}

*Corresponding author email: erichouston@cdrewu.edu

Received: 09 April 2018 / Revised: 16 April 2018 / Accepted: 16 April 2018 / Published: 22 April 2018

\begin{abstract}
Research indicates that stigma serves as a barrier to the recruitment of participants into mental health intervention studies. Some participants, such as those for depression intervention studies that target people with human immunodeficiency virus (HIV), may face multiple sources of stigma. The purpose of this brief report was to describe recruitment strategies used during the initial months of an ongoing preliminary pilot study designed to develop a web-based intervention for young African American and Latino gay and bisexual men living with HIV who reported symptoms of depression. We employed four primary recruitment strategies to identify potential participants in the Los Angeles metropolitan area for the study. These strategies included social media, referrals, direct contact, and recruitment flyers. Preliminary data indicated that recruitment efforts generated 57 responses from potential participants during the first four months of recruitment and study implementation. The monthly response rate from potential participants represented slightly more than $71 \%$ of the study's minimum level targeted for participant enrollment. Findings from this preliminary study are discussed in terms of the role of stigma as a barrier to mental health participant research recruitment. Implications for both depression research and clinical interventions are considered.
\end{abstract}

Keywords: Depression, HIV, stigma, participant recruitment, mental health research

\section{Introduction}

Depression is widespread and disproportionately affects people living with HIV and other chronic health conditions (Ali, Stone, Peters, Davies, \& Khunti, 2006; Gunn et al., 2010; Guthrie et al., 2016; Wagner et al., 2011). Findings from a study based on a nationally representative sample of people living with human immunodeficiency virus (HIV) in the United States found that $36 \%$ of participants had a probable diagnosis of major depressive disorder, a rate nearly five times greater than that of the general population (Bing et al., 2001). The adverse impact of depression on HIV medication adherence and engagement with care makes receiving treatment for depression critical. For many people living with HIV (PLH), however, depression is largely untreated (Asch et al., 2003; Shippy, Mendez, Jones, Cergnul, \& Karpiak, 2004). Low rates of treatment for depression in the HIV patient population have been attributed to several factors, including the stigma associated with both conditions, leading individuals to avoid pursuing or engaging in treatment for depression as well as participating in depression intervention research (Earnshaw, Bogart, Dovidio, \& Williams, 2013; Nichols et al., 2002; Reece, 2003; Shippy, Mendez, Jones, Cergnul, \& Karpiak, 2004). 
Further complicating depression research recruitment and treatment utilization is the prevalence of HIV among population groups that have been the target of negative attitudes and discrimination. HIV has a particularly high prevalence among men who have sex with men (MSM). MSM account for more than twothirds of new HIV infections nationally (CDC, 2017). Young MSM (YMSM), ages 18-29, represent 44\% of new infections nationally (CDC, 2012). African-American and Latino YMSM account for the bulk of these new infections (CDC, 2017; Leonard, Ragan, Gwadz, \& Aregbesola, 2014). Clearly, potential participants with depression often face multiple stressors and other sources of stigma that may also serve as barriers to recruitment efforts, including those connected to their ethnoracial, gender, sexual orientation, or class identity.

Little research has focused on how to reach and engage patients with depression and HIV who may be at the intersection of multiple social identities faced with stigma. Due to the negative impact of depression on the health status of people living with HIV, there is a need to better understand the types of recruitment strategies that could be used in research focused on improving the effectiveness and utilization of treatments for depression. Published reviews focusing on barriers to recruitment for depression trials have provided evidence of the impact of participant symptom presentation and severity, treatment preferences, views of research procedures, and depression stigma (Hughes-Morley, 2015). To aid in depression research recruitment efforts, however, there is a need for information on approaches that can be employed to reach specific patient populations faced with multiple stigmas.

In this brief report we describe recruitment strategies used in an ongoing preliminary pilot study for African American and Latino YMSM living with HIV who report mild to moderately severe depressive symptoms. The study was designed to develop an innovative web-based intervention that would use evidence-based approaches to address depressive symptoms and poor adherence in this vulnerable and hard-to-reach patient population. African American and Latino YMSM experience among the lowest rates of engagement with HIV care, treatment initiation, and antiretroviral therapy (ART) adherence. Research suggests that due to depressive symptoms, many YMSM of color either do not access traditional interventions they drop out prematurely (Du Bois, Johnson, \& Mustanski, 2012; Holloway, Rice, Gibbs, Winetrobe, Dunlap, \& Rhoades 2013; Rutledge, Roffman, Picciano, Kalichman, \& Berghuis, 2002; Thompson, Auslander, \& Alonzo, 2012).

\section{Methods}

\subsection{Summary}

Data analysis in this report was based on the first four months of participant recruitment for the study, which used a mixed method design to develop a web-based cognitive training intervention to address depressive symptoms and suboptimal HIV treatment adherence among African American and Latino YMSM (ages 18-29) in the Los Angeles metropolitan area. The intervention, Project STEP ("Steps Toward Embodying Positivity"), was developed in collaboration with HIV patients and care providers. The study received guidance and support from a community advisory board consisting of eight members. Advisory board members were consulted on recruitment procedures and strategies. The Institutional Review Board of Charles R. Drew University of Medicine and Science approved the study.

Participants were recruited for a focus group session to obtain feedback on an initial version of the webbased intervention and for a preliminary brief pilot in which individuals from the target population used the web-based intervention. Participants in the pilot were asked to use the intervention on a daily basis at home as well as a clinical setting for up to four weeks. Pilot study participants also receive information related to behavioral strategies for HIV treatment adherence, mood management, and alcohol and substance abuse prevention based on modules from a Centers for Disease Control (CDC) evidence-based intervention. The modules were delivered to participants via laptop computers and iPad devices during weekly visits with a study counselor. Study participants were asked to complete questionnaires to assess depressive symptoms, adherence, treatment motivation, self-efficacy, HIV stigma, internalized homophobia, and challenges they face with regard to medication management. Pilot study participants were 
Houston et al., Adv. J Social Sci.; Vol. 3 Issue 1, pp: 1-7, 2018

also asked to complete interviews regarding their views of the intervention upon completing their enrollment.

\subsection{Recruitment}

Recruitment for the study began during early December 2017. Recruitment goals included identifying and enrolling five to seven participants for a focus group and 15 participants for the pilot intervention. Participants were recruited using four primary strategies: 1) social media; 2) referrals; 3) direct recruitment; and 4) recruitment flyers. All participants were administered informed consent before being enrolled in the study. The way a participant learned about the study was determined at the time of screening.

\subsubsection{Social Media}

Research indicates that recruitment strategies using the Internet and social media have had relatively better outcomes than other strategies (Woodford, Bessant, \& Williams, 2011). We therefore placed recruitment ads and study announcements on social media and Internet sites used by the target population, including Craigslist, and dating apps, such as Grindr and Adam4Adam. Study announcements on Grindr and Adam4Adam identified Project STEP and indicated that African American and Latino YMSM (ages 18-29) users should contact the study, thereby following study guidelines that allow a passive recruitment approach on social networking and dating apps. We communicated with participants only if they initiated the contact. On Craigslist, we posted an ad in an employment section used by other research studies. The ad headline was "Seeking African American and Latino gay/bisexual men (18-29 y.o.)" and included the following text for pilot study recruitment: "Project STEP is seeking African American and Latino gay and bisexual men (ages 18-29 years old) to try a new app dealing with depression and HIV treatment. You will be asked to fill out questionnaires about yourself and use the app on a daily basis for four weeks. You will receive compensation if you join this research study." The ad indicated that participants could receive up to $\$ 224$ in incentives. Potential participants were provided with a phone number and email address that they could use to contact the study for additional information or to enroll. The text for focus group recruitment indicated that participants would be asked to provide feedback on the app rather than use it.

The study's website was also used to facilitate recruitment by providing participants with information on the intervention, research staff, and information and resources related to depression, HIV treatment, and other issues, such as housing and substance abuse treatment. Participants could also use the website to communicate with staff and schedule appointments. The website for our study was developed using Wix, a free website builder tool [www.mindsonhealth.org].

\subsubsection{Referrals}

We sought referrals from mental health professionals and providers of social services and medical care in the Los Angeles metropolitan area. We also sought referrals from our community advisory board. All individuals from whom we request referrals are given background on the study and provided with flyers for distribution to potential participants. Enrolled participants were also invited to refer those in their social networks to enroll in the study.

\subsubsection{Direct Recruitment}

We identified and enrolled potential participants through direct recruitment efforts at community events, agency drop-ins and support group meetings, clinic waiting rooms, and during community outreach activities with personnel from the OASIS Clinic at Charles R. Drew University. Study recruiters provided study information to potential participants and gathered contact information from interested individuals to screen for eligibility and schedule appointments.

\subsubsection{Recruitment Flyers}

Participants were recruited through English and Spanish language flyers distributed to individuals and posted at social-service agencies and medical clinics that provide services to the target population in the 
Los Angeles metropolitan area. Flyers, designed with text in a light green font on a white background, were also distributed at community events that attracted YMSM of color. Two different versions of the flyers were used for focus group and pilot study participants, stating that Project STEP was looking for African American and Latino gay and bisexual men living with HIV who would either give feedback on a webbased application (app) for depression and HIV treatment (focus group participants) or use the app on a daily basis for up to four weeks (pilot study participants). Participants were informed that they would be asked to complete brief questionnaires and given information on the study time commitment (e.g., attend two-hour focus group session; use app for up to four weeks). Flyers indicated that participants would be provided with an incentive and included a phone number and email address that potential participants could use to contact the study to enroll or obtain more information. Flyers used in this study were reviewed by focus group participants and our community advisory board.

\section{Results}

\subsection{Participant Recruitment}

Recruitment efforts during the first four months of study recruitment and implementation yielded a preenrollment database containing 57 individuals for focus group or pilot study participation. Overall, the ethnic representation of potential participants screened from our pre-enrollment database was $54 \%$ African American $(n=31)$ and $46 \%$ Latino $(n=26)$. Contact was made with all potential participants by study research coordinators, resulting in a screening rate for eligibility of approximately 14.25 individuals per month. Of those contacted, 47 individuals $(82.5 \%)$ were determined to be eligible. Ten individuals did not meet eligibility criteria due to age $(n=5)$, HIV status $(n=4)$, or both HIV status and MSM identification $(n=1)$. The ages of participants who failed to meet eligibility criteria based on age ranged from 31 to 44 $(\mathrm{M}=35.6)$.

Of the 47 potential participants screened as eligible, $25 \%(n=12)$ were enrolled for participation in focus group interviews $(n=5)$ or the pilot study $(n=7)$. The remaining potential participants $(n=35)$ consisted of 26 who could not be reached after the initial screening interview, and nine who indicated they were no longer interested or could not attend baseline interviews due to scheduling difficulties.

\subsection{Recruitment Strategies}

Social media generated the vast majority of responses from potential participants to recruitment efforts during the initial four months of the study $(\mathrm{n}=42 ; 74 \%)$. Potential participants who learned about the study through recruitment ads posted on Craigslist represented the bulk of these individuals $(n=29 ; 69 \%)$, followed by those reached through $\operatorname{Grindr}(n=12 ; 29 \%)$, and the project's website ( $n=1 ; 2.4 \%)$. There were no responses from potential participants to our recruitment efforts on Adam4Adam, an Internet dating site popular among MSM.

Recruitment contacts through referrals from health and social service providers accounted for the second largest number of responses from potential participants $(n=8 ; 14 \%)$. Referrals came primarily from two social-service agencies in the Los Angeles metropolitan area that were identified as possible recruitment venues based on their outreach and connections with the target population. Direct recruitment activities represented the third largest source of potential participants, accounting for approximately $12 \%(n=7)$ of the pre-enrollment database. Recruitment flyers are posted and distributed at venues where individuals from the targeted population could be found. Flyers are also distributed during direct recruitment. Potential participants, however, have not identified recruitment flyers as the primary way they learned about the study.

\subsection{Preliminary Outcomes by Recruitment Source}

The source of the 12 participants who enrolled in the study during the first four months of recruitment and study implementation was evenly divided between social media recruitment efforts $(n=6)$ and referral sources $(\mathrm{n}=6)$. Of individuals who were found to be ineligible for study participation following screening, 
Houston et al., Adv. J Social Sci.; Vol. 3 Issue 1, pp: 1-7, 2018

$90 \%(n=9)$ learned about the study through Craigslist while the remainder $(10 \% ; n=1)$, learned about the study through a referral source.

\section{Discussion}

Developing strategies to effectively recruit participants for mental health research is a longstanding problem (Hughes-Morley, Young, Waheed, Small, Bower, 2015; Waheed, Hughes-Morley, Woodham, Allen, \& Bower, 2015; Woodford, Bessant, Williams, 2011). In this brief report, we described recruitment strategies used in a current and ongoing preliminary pilot study designed to develop a web-based depression intervention for depression among African-American and Latino YMSM living with HIV. Previous research has reported challenges involved in recruiting potential participants into mental health research due to the impact of stigma (Hughes-Morley, Young, Waheed, Small, Bower, 2015; Kanuch, Cassidy, Dawson, Athey, Fuentes-Casiano, \& Sajatovic 2016; Loue \& Sajatovic, 2008; Patel, Doku, \& Tennakoon, 2003; Waheed, Hughes-Morley, Woodham, Allen, \& Bower, 2015; Woodford, Bessant, Williams, 2011). While a psychiatric diagnoses or symptoms or mental illness may serve as a barrier to participant research recruitment and enrollment, the presence of other sources of stigma may represent additional and often unaddressed barriers. In our study, participants targeted for recruitment have represented individuals from groups that face multiple sources of social stigma based on mental illness, ethnicity, sexual orientation, and disease. Our preliminary findings suggest that social media and referrals may represent the most productive strategies for reaching individuals from these vulnerable and hard-to-reach population groups.

Social media strategies generated the vast majority of responses from potential participants $(66 \%)$ followed by referrals from health and social service providers, with $28 \%$ of responses. Direct recruitment activities accounted for the remainder, with six percent of total responses from potential participants. These early findings were consistent with other research that indicate the effectiveness of these particular recruitment strategies in mental health participant research recruitment as well as behavioral research targeting participants from other socially stigmatized groups (Martinez et al., 2014; Waheed, Hughes-Morley, Woodham, Allen, \& Bower, 2015).

\section{Conclusion}

Difficulties in the recruitment and retention of participants for depression intervention research pose a threat to the timely and successful completion of clinical trials. These recruitment difficulties could lead to delays in the dissemination of findings pertaining to the effectiveness of alternative treatment approaches. Given that the findings reported here were from a small, ongoing preliminary study, they must be viewed with caution. As our recruitment efforts continue, data may emerge that show other recruitment strategies (e.g., flyers, direct recruitment) as relatively effective or viable options. Despite this caveat, our findings are noteworthy. The pace at which potential participants were identified in our preliminary project, a small mental health study with limited resources, was steady. Our findings showed that recruitment efforts during the initial four months of recruitment for the current study generated responses from an average of 14.25 individuals each month. This monthly response rate from potential participants represents slightly more than $71 \%$ of the minimum sample targeted for the focus group and pilot study phases of the project. Thus, the overall impact of the strategies we have employed suggests a blend that may be favorable with regard to mental health study recruitment involving participants faced with multiple sources of social stigma.

\section{Declarations}

\subsection{Acknowledgments}

None

\subsection{Study Limitation}

Findings reported in this manuscript are preliminary and based on a small, ongoing study. 


\subsection{Ethical Approval}

This study was approved by the Institutional Review Board (IRB) of Charles R. Drew University of Medicine and Science (IRB \#16-11-2493-02)

\subsection{Informed Consent}

All participants in the study were administered informed consent.

\subsection{Funding Sources}

Dr. Houston is supported by a grant from the National Institute on Minority Health and Health Disparities (S21 MD000103; Sustaining Faculty Development and Community Engagement; David M. Carlisle, M.D., Principal Investigator). This research was supported by Grant 5U54MD007598 from NIMHD to Accelerating Excellence in Translational Science (AXIS) at Charles R. Drew University of Medicine and Science (Jaydutt V. Vadgama, Ph.D., Principal Investigator). The content is solely the responsibility of the authors and does not necessarily represent the official views of NIMH or the NIH.

\subsection{Competing Interests}

The authors report that there are no competing interests.

\section{How to Cite this Article:}

Houston, E., Argueta, C., Lacey, J., Mukherjee, S., \& Breda-Hill, K. (2018, April 22). Reaching Mental Health Research Participants with Multiple Stigmas; A Description of Strategies Used in a Depression Intervention Study for YMSM of Color with HIV. Advanced Journal of Social Science, 3(1), 1-7. https://doi.org/10.21467/ajss.3.1.1-7

\section{References}

Ali, S., Stone, M., Peters, J., Davies, M., \& Khunti, K. (2006). The prevalence of co-morbid depression in adults with Type 2 diabetes: A systematic review and meta-analysis. Diabetic Medicine, 23, 1165-73.

Asch, S. M., Kilbourne, A. M., Gifford, A. L., Burnam, M. A., Turner, B., Shapiro, M. F., \& Bozzette, S. A. (2003). Underdiagnosis of depression in HIV. Journal of General Internal Medicine, 18, 450-460.

Bing, E.G., Burnam, M.A., Longshore, D., Fleishman, J.A., Sherbourne, C.D., London, A.S., Turner, B.J., Eggan, F., Beckman, R., Vitiello, B., Morton, S.C., Orlando, M., Bozzette, S.A., Ortiz-Barron, L., \& Shapiro, M. (2001). Psychiatric disorders and drug use among human immunodeficiency virus-infected adults in the United States. Archives of General Psychiatry, 58, 721-728.

CDC (2017). HIV Surveillance Report, 2016, Vol. 28.

CDC (May 2012). HIV among gay and bisexual men

Du Bois S, Johnson S, Mustanski B. Examining racial and ethnic minority differences among YMSM during recruitment for an online HIV prevention intervention study (2012). AIDS and Behavior, 16(6), 1430-1435.

Earnshaw, V. A., Bogart, L. M., Dovidio, J. F., \& Williams, D. R. (2013). Stigma and Racial/Ethnic HIV Disparities: Moving Toward Resilience. The American Psychologist, 68(4), 225-236.

Gunn, J., Ayton, D., Densley, K., Pallant, J., Chondros, P., Herrman, H., \& Dowrick, C.F. (2010). The association between chronic illness, multimorbidity and depressive symptoms in an Australian primary care cohort. Social Psychiatry and Psychiatric Epidemiology, 47, 175-84.

Guthrie, E.A., Dicken, C., Blakemore, A., Watson, J., Chew-Graham, C., Lovell, K., Afzal, C., Kapur, N., \& Tomenson, B. (2016). Depression predicts future emergency hospital admissions in primary care patients with chronic physical illness. Journal of Psychosomatic Research, 82, 54-61.

Holloway, I.W., Rice, E., Gibbs, J., Winetrobe, H., Dunlap, S., \& Rhoades, H. (2013). Accessibility of smartphone application-based HIV prevention among young men who have sex with men. AIDS and Behavior, 18(2), 285-296.

Hughes-Morley, A., Young, B., Waheed, W., Small, N., \& Bower, P. (2015). Factors affecting recruitment into depression trials: Systematic review, meta-synthesis and conceptual framework. Journal of Affective Disorders, 172:274-90.

Kanuch, S. W., Cassidy, K. A., Dawson, N. V., Athey, M., Fuentes-Casiano, E., \& Sajatovic, M. (2016). Recruiting and retaining individuals with serious mental illness and diabetes in clinical research: Lessons learned from a randomized, controlled trial. Journal of Health Disparities Research and Practice, 9(3), 115-126

Leonard, N. R., Ragan, S., Gwadz, M. V., \& Aregbesola, T. (2014). HIV testing patterns among urban YMSM of color. Health Education \& Behavior, 41(6), 673-681.

Loue, S., \& Sajatovic M. (2008). Research with severely mentally ill Latinas: Successful recruitment and retention strategies. Journal of Immigrant and Minority Health, 10(2),145-153.

Martinez, O., Wu, E., Shultz, A.Z., Capote, J., Rios, J.L., R.J, Sandfort ,T., Manusov, J., Ovejero, H., Carballo-Dieguez, A., Baray, S.C., Moya, E., Matos, J.L., DelaCruz, J.J., Remien, R.H., Rhodes, S.D. (2014). Still a hard-to-reach population? using social media to recruit Latino gay couples for an HIV intervention adaptation study. Journal of Medical Internet Research, 16(4):e113.

Nichols, J.E., Speer, D., Watson, B., Watson, M., Vergon, T., Vallee, C., Meah, J. (2002). Aging with HIV: Psychological, Social, and Health Issues. Academic Press; San Diego.

Patel, M., Doku, V., \& Tennakoon, L. (2003). Challenges in recruitment of research participants. Advances in Psychiatric Treatment, 9(3), 229-238.

Reece, M. (2003). HIV-related mental health care: Factors influencing dropout among low-income, HIV-positive individuals. AIDS Care, 15, 707-716. 
Houston et al., Adv. J Social Sci.; Vol. 3 Issue 1, pp: 1-7, 2018

Rutledge, S., Roffman, R., Picciano, J., Kalichman, S., \& Berghuis, J. 2002. HIV prevention and attrition: Challenges and opportunities. AIDS and Behavior 6(1), 69-82.

Shippy, R. A., Mendez, D., Jones, K., Cergnul, I., \& Karpiak, S. E. (2004). S-adenosylmethionine (SAM-e) for the treatment of depression in people living with HIV/AIDS. BMC Psychiatry, 4, 38.

Thompson, R.G., Auslander, W.F., \& Alonzo, D. (2012). Individual-level predictors of nonparticipation and dropout in a life-skills HIV prevention program for adolescents in foster care. AIDS Education and Prevention, 24(3), 257-69 .

Wagner, G.J., Goggin, K., Remien, R.H., Rosen, M.I., Simoni, J., Bangsberg, D.R., Liu, H., \& MACH14 Investigators (2011) A closer look at depression and its relationship to HIV antiretroviral adherence. Annals of Behavioral Medicine, 42(3), 352-360.

Waheed, W., Hughes-Morley, A., Woodham, A., Allen, G., \& Bower, P. (2015). Overcoming barriers to recruiting ethnic minorities to mental health research: a typology of recruitment strategies. BMC Psychiatry, 15, 101.

Woodford, J.F.P., Bessant, M., \& Williams, C. (2011). Recruitment into a guided internet based CBT (iCBT) intervention for depression: Lesson learnt from the failure of a prevalence recruitment strategy. Contemporary Clinical Trials, 32, 641-8.

Publish your research article in AIJR journals-

$\checkmark \quad$ Online Submission and Tracking

$\checkmark$ Peer-Reviewed

$\checkmark \quad$ Rapid decision

$\checkmark \quad$ Immediate Publication after acceptance

$\checkmark \quad$ Articles freely available online

$\checkmark \quad$ Retain full copyright of your article.

Submit your article at journals.aijr.in
Publish your books with AIJR publisher-

$\checkmark \quad$ Publish with ISBN and DOI.

$\checkmark$ Publish Thesis/Dissertation as Monograph.

$\checkmark \quad$ Publish Book Monograph.

$\checkmark \quad$ Publish Edited Volume/ Book.

$\checkmark \quad$ Publish Conference Proceedings

$\checkmark \quad$ Retain full copyright of your books.

Submit your manuscript at books.aijr.org 